$\begin{gathered}\text { Revista do Departamento de Geografia } \\ \text { Universidade de São Paulo } \\ \text { www.revistas.usp.br/rdg } \\ \text { Vovista do Departamento de Geografia USP } \\ \text { ISSN 2236-2878 }\end{gathered}$
Volume Especial (2016)

\title{
O CLIMA E A POLUIÇÃO DO AR POR PTS EM CURITIBA -PR
}

\section{THE CLIMATE AND THE TSP AIR POLLUTION AT CURITIBA - PR}

\author{
Francisco Assis Mendonça \\ Universidade Federal do Paraná \\ chico@ufpr.br \\ Francisco Jablinski Castelhano \\ Universidade Federal do Paraná \\ fjcastelhano@gmail.com
} Recebido (Received): 13/09/2016
DOI:11606/rdg.v1i0.120677

\begin{abstract}
Resumo: A queda na qualidade do ar é um dos principais problemas ambientais em centros urbanos pelo mundo. As condições climáticas se relacionam a má qualidade do ar e tem impacto direto sobre o processo de dispersão e acúmulo de poluentes. $\mathrm{O}$ presente estudo da relação entre a qualidade do ar e o clima urbano foi desenvolvido com a aplicação da proposta de SCU - Sistema Clima Urbano - de Monteiro (1976). A cidade de Curitiba (sul do Brasil), mantem uma rede de monitoramento da qualidade do ar (Instituto Ambiental do Paraná - IAP). Para compreender como se dá a relação supracitada, dados horários de PTS (Partículas Totais em Suspensão) foram coletados em três estações oficiais de monitoramento distintas, localizadas na zona urbana da cidade. Estes dados foram tratados com o auxílio do software $\mathrm{R}$ e correlacionados com dados meteorológicos através do índice de Pearson. Com o intuito de analisar a dinâmica temporal do poluente foram aplicados delays de até 24 horas ao teste, tentando compreender se as correlações são imediatas ou tardias. Além disso, para a análise atmosférica, foram realizadas análises dos tipos de tempo usando a metodologia da Análise Rítmica (Monteiro,1971). Os resultados sugerem que a variável que mais influencia na dinâmica do poluente é a umidade relativa do ar. Todas as variáveis apresentaram correlações negativas com o PTS, e as concentrações mais altas se encontram sob atuação de sistemas atmosféricos extratropicais.
\end{abstract}

Palavras-chave: Qualidade do ar, PTS, Tipos de Tempo, Condições Climáticas, Curitiba.

\begin{abstract}
The decrease of air quality it is one of the main environmental problems in the urban centers through the world. The climate conditions, related to some determinants factors of the air quality have a direct impact over the process of dispersion and accumulation of the pollutants. The relation between air quality and climate is focused in this paper under da SCU - Urban Climate System - as proposed by Monteiro (1976). The city of Curitiba, south of Brazil, keeps a monitoring network of air quality (Environmental Institute of Paraná - IAP). To understand how this relation works hourly data of TSP (Total Suspended Particles) pollutant were collected from three different official monitoring stations located in the urban zone of the city. This data were treated with the statistical analysis software $R$, and the correlations between the meteorological factors and the pollutant were tested using the Pearsons Index. In order to analyze the temporal dynamics of the TSP, were inserted in the tests a time lag until 24 hours, trying to understand if the correlation is immediate or late. Also, for the atmospheric dispersion, were made a weather types analysis using the Rhytmic Analyse method (Monteiro, 1971). The results suggest that the variable with most correlation is relative humidity. All of this variables presents a negative correlation with the TSP index, and higher concentrations under extra-tropical atmospheric systens.
\end{abstract}

Keywords: Air Quality, TSP, Weather types, Climate conditions, Curitiba. 


\section{INTRODUÇÃO}

O clima constitui-se num elemento de considerável influencia sobre o homem enquanto individuo e enquanto sociedade. Compreendido como condicionante chave para uma série de aspectos ligados a saúde e qualidade de vida, faz-se cada vez mais necessário o aprofundamento de pesquisas acerca das interações entre o clima e a sociedade humana.

Os tipos de tempo observados em um dado sítio constituem fator crucial no entendimento da dispersão ou concentração de poluentes atmosféricos (HUFTY, 2001; MCCORMAC, 1971). Monteiro (1976), de forma específica e aprofundada, já chamava atenção à necessária compreensão sobre a qualidade do ar nas cidades como aspecto fundamental para a promoção da qualidade da vida urbana no Brasil.

Neste momento em que a Revista do Departamento de Geografia homenageia os 40 anos da contribuição de Monteiro (1976, 2003 e 2015) relativa ao estudo do SCU - Sistema Clima Urbano, soa-nos instigante apresentar esta contribuição relacionada ao subsistema físico-químico do SCU, aquele que recebeu o menor número de contribuições neste período (MENDONÇA, 2003; 2015). Vários fatores respondem pela pequena quantidade de estudos vinculada a este subsistema, dos quais se destaca os valores elevados de equipamentos para aferição da qualidade do ar, bem como das analises laboratoriais dos filtros, etc. A insuficiência de recursos das instituições públicas de pesquisa brasileiras relegaram para um segundo plano a investigação da atmosfera urbana no quesito poluição do ar, donde um subsistema ainda pouco explorado no Brasil.

Os níveis de poluição atmosférica em áreas urbanas apresentam diferentes valores e espacialidades, que estão na dependência de vários fatores. Dentre eles destacam-se a urbanização, a industrialização, o sítio urbano, as áreas verdes, a quantidade e o fluxo de veículos, as condições meteorológicas, etc. (MONTEIRO, 1976; MENDONÇA e DANNI-OLIVEIRA, 2007); ou seja, a função, a forma e a estrutura urbana desempenham importante papel na concentração ou dispersão de poluentes na atmosfera.

O clima atua, portanto, como um fator que pode condicionar a dispersão ou acumulo de poluentes em uma dada localidade (MONTEIRO, 1976; 2015). Derisio (2012) cita o episódio do Vale do Meuse (Bélgica), nos anos 1930, como um exemplo em que tanto foram observados altos índices de emissões quanto baixos de dispersão associados diretamente a uma sequencia de dias com tempo estável. DanniOliveira (2000 e 2007), em seu estudo sobre a poluição do ar na cidade de Curitiba, evidencia a dificuldade em estabelecer relações diretas entre os tipos de tempo e a qualidade do ar, sugerindo, contudo, uma maior frequência de concentração de poluentes quando do domínio de sistemas extratropicais.

A relação entre condições meteorológicas e qualidade do ar constituiu tema de interesse de Derisio (2012), Akpinar et al. (2009), Guthjar (2002), Romero et al. (1999) dentre outros, que apontaram uma correlação negativa entre os níveis de poluição e a umidade relativa do ar, as precipitações e a velocidade dos ventos. Aqui outra importante contribuição de MONTEIRO (1971) ao propor a análise rítmica dos tipos de tempo, metodologia fundamental para se compreender o processo de dispersão de poluentes em escala temporal e espacial fina.

As Partículas Totais em Suspensão (PTS) configuram-se num dos poluentes mais presentes nos ambientes urbanos, pois, são frutos diretos da queima de combustíveis fosseis. O excesso deste poluente na atmosfera desdobra-se em consideráveis consequências para a saúde humana; Monteiro (1976), Boubel et al. (1994) e Danni-Oliveira (2000), dentre inúmeros outros, citam danos aos sistemas circulatórios, oftalmológicos e respiratórios como os principais.

Considerando o subsistema físico-químico do SCU o presente estudo coloca em evidencia uma abordagem da correlação entre a urbanização do Aglomerado Urbano de Curitiba (AUC) e os níveis de Partículas Totais em Suspensão (PTS), com a finalidade de se compreender quais as variáveis climáticas e as situações atmosféricas apresentam maior influência na concentração deste poluente e sob quais condições se dá tal relação.

A área de estudo desta pesquisa conta com uma rede de 11 estações de monitoramento da qualidade do ar, dispersas em 03 municípios (Curitiba, Colombo e Araucária - Figura 1). A cidade de Curitiba constitui o núcleo urbano central da RMC - Região Metropolitana de Curitiba, capital do Estado do Paraná, com população de cerca de 2 milhões e de 3,5 milhões de habitantes, respectivamente; a área situa-se nas 
proximidades do Trópico de Capricórnio, a aproximadamente $900 \mathrm{~m}$ de altitude e a 100km do oceano Atlântico, sob o domínio do Clima Tropical de Altitude (MENDONÇA, 2012).

A indústria e os serviços, setores secundário e terciário da economia, compõem a principal função do AUC - Aglomerado urbano de Curitiba - que conta com cerca de 3 milhões de habitantes. A qualidade do ar da área urbana tem apresentado momentos de alta concentração de poluentes nas últimas décadas, notadamente após a intensificação da industrialização, da urbanização e do fluxo de veículos.

\section{MÉTODOS E TÉCNICAS}

No presente estudo foram analisados dados de PTS - Partículas Totais em Suspensão - provenientes de três estações da rede oficial de monitoramento da qualidade do ar do Estado do Paraná na RMC - Região Metropolitana de Curitiba, operadas pelo Instituto Ambiental do Paraná (IAP), referentes ao período de 2004 a 2012. Duas estações estão localizadas no setor leste (Estação I - Boqueirão) e central (Estação II - Praça Ouvidor Pardinho) da cidade de Curitiba, e a terceira (Estação III - REPAR) está localizada no município de Araucária (Figura 1).

A localização de cada estação representa uma realidade espacial urbana distinta. O entorno da Estação I é caracterizado por uma área urbana com médio trafego de veículos, indústrias de pequeno porte e baixa verticalização. O entorno da Estação II apresenta alto trafego de veículos, urbanização densa com poucas áreas verdes e intensa verticalização. A Estação III localiza-se junto ao grande aglomerado de indústrias petroquímicas do setor sul da cidade, com baixa densidade populacional, alto número de indústrias pesadas e próxima a grandes vias de circulação de veículos.

Os dados meteorológicos utilizados neste estudo - temperatura, vento, umidade e precipitação correspondentes ao mesmo período dos dados de PTS, foram fornecidos pelo SIMEPAR - Sistema Meteorológico do Paraná. A estação meteorológica está localizada no setor centro-leste da cidade, no interior da área urbana.

A confecção de boxplots possibilitou a visualização dos padrões mensais do comportamento dos poluentes atmosféricos analisados por estação de maneira clara, e o calculo das médias horarias por dia da semana revelou ciclos diários e semanais do PTS.

Os dados referentes ao PTS foram correlacionados aos dados meteorológicos do mesmo período, na escala horária, com a finalidade de se identificar as variáveis que apresentam maior correlação com os níveis de qualidade de ar.

Além disso, com o objetivo de observar a situação atmosférica geral em momentos de alto nível de PTS e proporcionar uma analise conjunta, foram selecionadas três semanas entre os anos de 2011 e 2012, nas quais os níveis dos poluentes encontraram-se particularmente altos.

A abordagem das condições climáticas teve por base o método da análise rítmica dos tipos de tempo (MONTEIRO, 1971; MENDONÇA e DANNI-OLIVEIRA, 2007), que possibilita a identificação diária dos tipos de tempo a partir dos elementos climáticos e da situação sinótica do local de estudo.

O tratamento estatístico dos dados foi elaborado através do software R, versão 3.2.2, e com o auxilio do pacote de dados Openair (CARSLAW e ROPKINS, 2012). Optou-se por realizar uma correlação linear simples entre as variáveis climáticas e os dados de PTS. Por tratar-se de variáveis numéricas e não categóricas, optou-se pelo calculo de correlação de Pearson. Ademais, foram adicionados atrasos de até 24 horas aos valores de poluição em relação aos de clima. Para validar as correlações obtidas foram realizados testes de p-valor com níveis de significância de $1 \%$. 


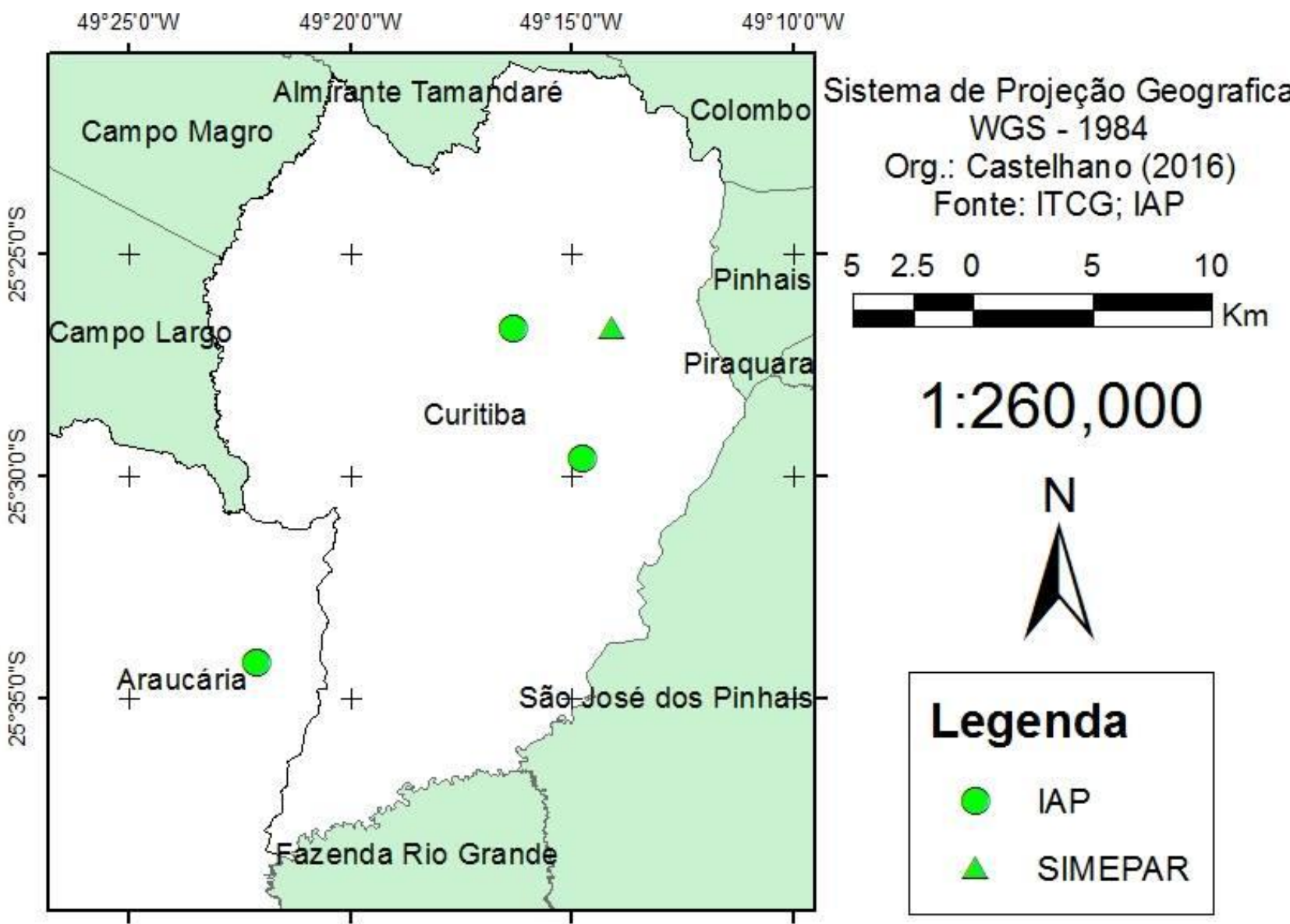

Figura 1: Curitiba: Localização das estações meteorológica e de monitoramento da qualidade do ar.

\section{TIPOS DE TEMPO E POLUIÇÃO POR PTS EM CURITIBA}

\section{Variação espacial do PTS em Curitiba}

A poluição do ar por PTS na área de estudo compromete a qualidade de vida dos habitantes, pois ultrapassa, em vários momentos (Figura 2), os limites estipulados pela legislação vigente no Brasil (150 e $240 \mu \mathrm{g} / \mathrm{m}^{3}$, primário e secundário respectivamente). O pico foi observado na Estação III - REPAR, que atingiu $1210 \mu \mathrm{g} / \mathrm{m}^{3}$ no dia 29/07/2005. Nas demais estações os maiores valores foram registrados em 11/02/2002 na Estação II - Praça Ouvidor Pardinho (507,8 $\left.\mu \mathrm{g} / \mathrm{m}^{3}\right)$ e em 06/07/2007 na Estação I - Boqueirão $\left(758,8 \mu \mathrm{g} / \mathrm{m}^{3}\right)$.

Os valores de PTS apresentam uma considerável diferenciação espacial na área urbana de Curitiba, mesmo em se considerando a pequena distancia entre elas. A Estação III - REPAR é que apresenta a pior qualidade do ar quando comparada às outras duas, seguida pela Estação II - Praça Ouvidor Pardinho e, finalmente, pela Estação I Boqueirão. Esta variação espacial da concentração de PTS reflete, dentre outros, a associação entre a industrialização e o fluxo de veículos que é mais forte na Estação III e menor nas demais. Deve-se ressaltar ainda uma grande falha na captação de dados da Estação I principalmente, e na Estação III, devido a problemas de manutenção das mesmas. 

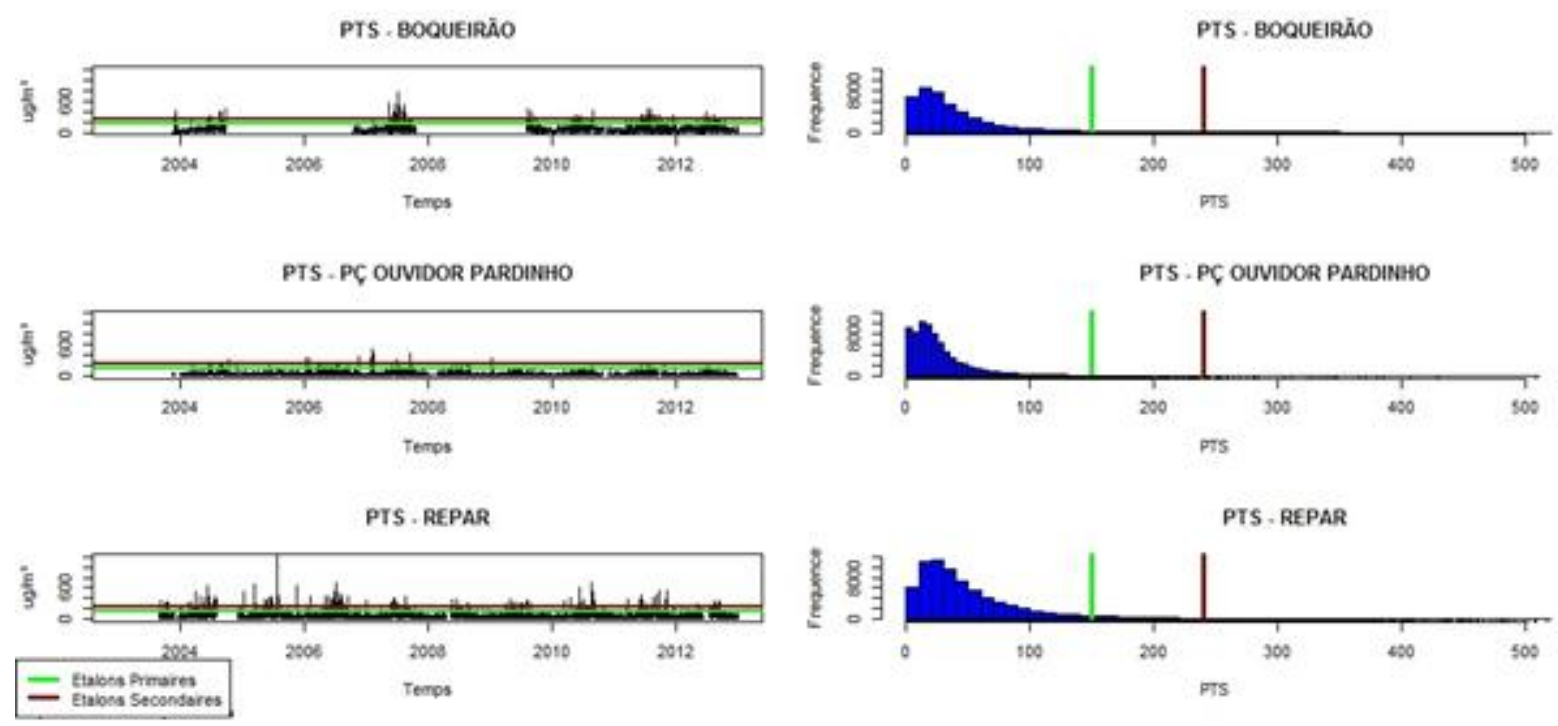

Figura 2: Curitiba - Poluição do ar por PTS 2004-2012.

Para o PTS não existe uma legislação de controle especifica na União Europeia nem no Brasil. Em relação ao material particulado mais fino (PM 10), a diferença nas legislações é grande, enquanto que as agencias europeias e norte-americanas estabeleceram um limite de $50 \mu \mathrm{g} / \mathrm{m}^{3}$ em 24 horas, a legislação brasileira aponta $150 \mu \mathrm{g} / \mathrm{m}^{3}$ para o mesmo período. Já para o PM 2,5 a legislação brasileira ainda esta a ser discutida e até o momento não há nada definido legalmente sobre seus limites primários ou secundários.

A Figura 3 evidencia a oscilação mensal do poluente PTS nas três estações analisadas neste estudo.
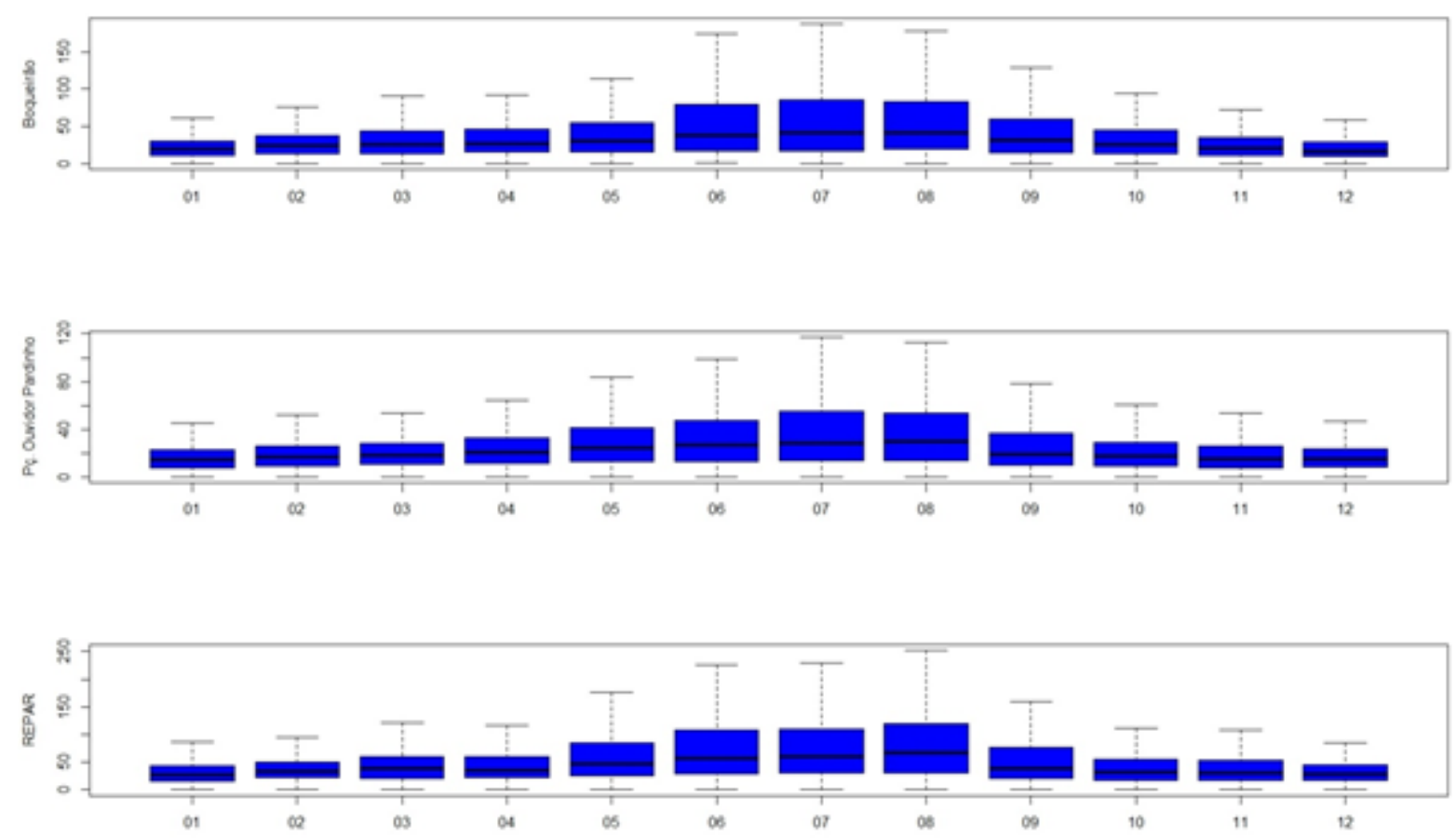

Figura 3: Curitiba - Oscilação Mensal de PTS $\left(\mu \mathrm{g} / \mathrm{m}^{3}\right)$.

Percebe-se uma relativa semelhança na variação dos poluentes nas três estações ao longo de um ano, com um período de pico bem salientado entre os meses de junho e agosto, e um período de baixos valores entre novembro e fevereiro. Novamente observa-se uma grande diferença nos valores absolutos, com a 
Estação III REPAR apresentando maiores valores, seguido pela Estação I - Boqueirão e por fim a Estação II - Praça Ouvidor Pardinho.

Afunilando a escala para semanal/horária constata-se, de maneira geral, um comportamento semelhante entre as estações (Figura 4). As médias registradas em $\mu \mathrm{g} / \mathrm{m}^{3}$ revelam ao longo de um dia dois picos em momentos distintos, o primeiro entorno de $10 \mathrm{~h}$ da manhã enquanto que o segundo, sempre mais significativo que o primeiro, ocorre próximo as $21 \mathrm{~h}$ e $22 \mathrm{~h}$. Ambos estão relacionados aos períodos de maior tráfego de veículos. A influência dos veículos nestes valores também é registrada quando observa-se a queda significativa nos níveis de PTS nos finais de semana em todas as estações analisadas.
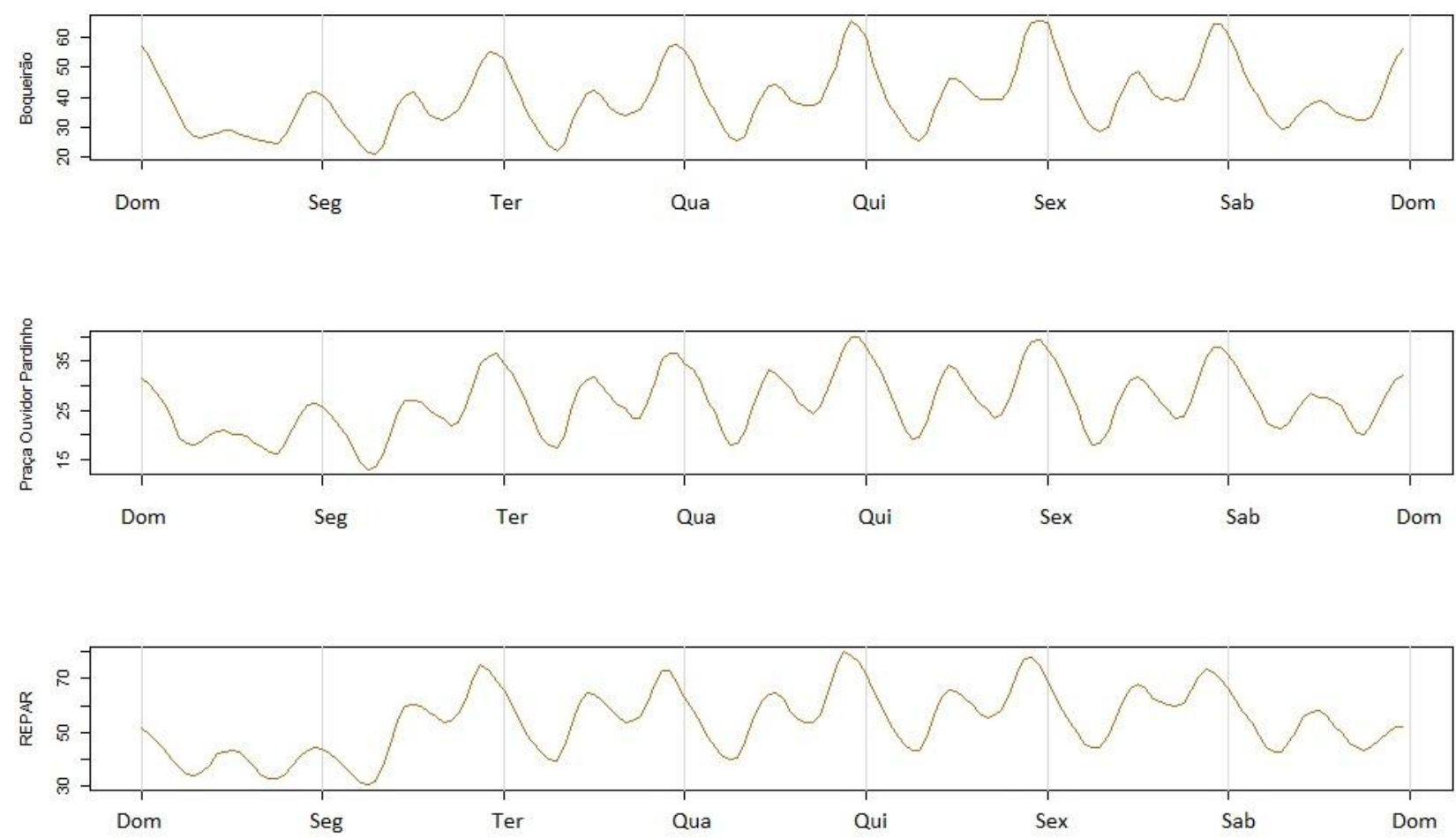

Figura 4: Curitiba - Oscilação Semanal/Horária de PTS $\left(\mu \mathrm{g} / \mathrm{m}^{3}\right)$.

\section{Correlações entre PTS e variáveis meteorológicas}

Os valores de correlação entre PTS e algumas variáveis meteorológicas obtidas através do Índice de Pearson (Tabela 1) apontam que a umidade relativa do ar e a velocidade do vento são aquelas que desempenham maior influência nos níveis de PTS.

A umidade do ar e a velocidade do vento apresentaram valores de correlação negativa, o que indica que quanto maiores os seus valores, menores os registros de PTS, sendo o oposto também verdadeiro. Aplicando o teste de p-valor a estes indicies de correlação, observou-se um alto valor de significância, o que confirma uma expressiva probabilidade de confiabilidade desta correlação. Tais valores são significantes principalmente devido à grande amostra a qual foram aplicados os testes de correlação.

A correlação entre índices de chuva e PTS revelou-se baixa nas três estações de monitoramento da qualidade do ar, da mesma forma para os valores de temperatura nas estações I-Boqueirão e II-Praça Ouvidor Pardinho. Na estação REPAR, contudo, os valores encontrados para a temperatura foram diferentes das demais, apresentando alta significância no teste de p-valor e correlação acima das demais, assim como para a velocidade do vento. 
Tabela 1: Curitiba - Correlação Pearson PTS/Variáveis meteorológicas

\begin{tabular}{cccc}
\hline & Estação I & Estação II & Estação III \\
\hline $\begin{array}{c}\text { Velocidade do } \\
\text { Vento }\end{array}$ & $-0,07$ & $-0,11$ & $-0,08$ \\
$\begin{array}{c}\text { Umidade } \\
\text { Relativa }\end{array}$ & $-0,21$ & $-0,21$ & $-0,33$ \\
Precipitação & $-0,05$ & $-0,05$ & $-0,06$ \\
T.Máx & 0,006 & 0,04 & 0,13 \\
T. Med & $-0,01$ & 0,03 & 0,11 \\
T. Min & $-0,02$ & 0,02 & 0,10 \\
\hline
\end{tabular}

\section{Atrasos nas correlações}

Os testes de correlação com aplicação de atrasos para as variáveis precipitação e temperaturas máxima, média e mínima tiveram muito pouca diferença nas três estações (tabela 1).

Para a velocidade do vento observou-se que, conforme se aumentava o atraso os valores decrescem, o que indica que tal variável apresenta uma correlação mais imediata ao PTS. Tal fato foi observado novamente nas três estações de maneira similar.

Em relação à umidade relativa do ar, os resultados foram diferentes. Notou-se a princípio uma queda, seguida de uma elevação nos valores de correlação até se chegar a um atraso de 17 horas para as estações REPAR e Praça Ouvidor Pardinho, e de 18 horas para a estação Boqueirão, quando os mesmos voltam a decrescer.

A Tabela 2 aponta os valores obtidos com a aplicação da correlação de Pearson com atraso para a variável umidade relativa. Chama a atenção, além do padrão acima mencionado, o fato de que para as estações Boqueirão e Praça Ouvidor Pardinho os índices de correlação com atraso chegam a ser relativamente maiores do que os sem atraso, indicando que tal fator exerce uma correlação maior com a poluição após um dado atraso e não de maneira imediata.

Tabela 2: Curitiba - Correlação de Pearson entre Umidade Relativa e PTS com atrasos de 01 a 23 horas.

\begin{tabular}{ccccccccccccc}
\hline Estação & $\mathbf{0}$ & $\mathbf{1}$ & $\mathbf{2}$ & $\mathbf{3}$ & $\mathbf{4}$ & $\mathbf{5}$ & $\mathbf{6}$ & $\mathbf{7}$ & $\mathbf{8}$ & $\mathbf{9}$ & $\mathbf{1 0}$ & $\mathbf{1 1}$ \\
\hline I & $-0,21$ & $-0,19$ & $-0,17$ & $-0,15$ & $-0,13$ & $-0,12$ & $-0,11$ & $-0,10$ & $-0,09$ & $-0,09$ & $-0,11$ & $-0,13$ \\
II & $-0,21$ & $-0,20$ & $-0,19$ & $-0,18$ & $-0,17$ & $-0,16$ & $-0,14$ & $-0,13$ & $-0,13$ & $-0,13$ & $-0,14$ & $-0,16$ \\
III & $-0,33$ & $-0,32$ & $-0,29$ & $-0,27$ & $-0,25$ & $-0,23$ & $-0,21$ & $-0,18$ & $-0,16$ & $-0,15$ & $-0,14$ & $-0,15$ \\
\hline & $\mathbf{1 2}$ & $\mathbf{1 3}$ & $\mathbf{1 4}$ & $\mathbf{1 5}$ & $\mathbf{1 6}$ & $\mathbf{1 7}$ & $\mathbf{1 8}$ & $\mathbf{1 9}$ & $\mathbf{2 0}$ & $\mathbf{2 1}$ & $\mathbf{2 2}$ & $\mathbf{2 3}$ \\
\hline I & $-0,17$ & $-0,21$ & $-0,26$ & $-0,30$ & $-0,34$ & $-0,36$ & $-0,37$ & $-0,37$ & $-0,35$ & $-0,33$ & $-0,30$ & $-0,27$ \\
II & $-0,19$ & $-0,22$ & $-0,25$ & $-0,27$ & $-0,28$ & $-0,28$ & $-0,27$ & $-0,25$ & $-0,23$ & $-0,20$ & $-0,18$ & $-0,16$ \\
III & $-0,16$ & $-0,18$ & $-0,21$ & $-0,23$ & $-0,24$ & $-0,25$ & $-0,25$ & $-0,25$ & $-0,24$ & $-0,23$ & $-0,22$ & $-0,22$ \\
\hline
\end{tabular}

\section{Análise Rítmica e os níveis de PTS}

\section{A semana de 08/07 a 15/07/2011}

O inicio da primeira semana analisada apresentou estabilidade atmosférica sob a atuação da MPA (Massa Polar Atlântica), o que foi alterado após o dia 11/07 com a passagem de uma Frente e a sequencial atuação de uma MTA (Massa Tropical Atlântica). Os ventos foram predominantes de leste e nordeste durante toda a semana, sendo que ocorreu também um pequeno evento de chuva (20 $\mathrm{mm}$ dia 11/07) com temperaturas relativamente baixas (mínima de $2,2^{\circ} \mathrm{C}$ e máxima $26,4^{\circ} \mathrm{C}$ - Figura 5). 


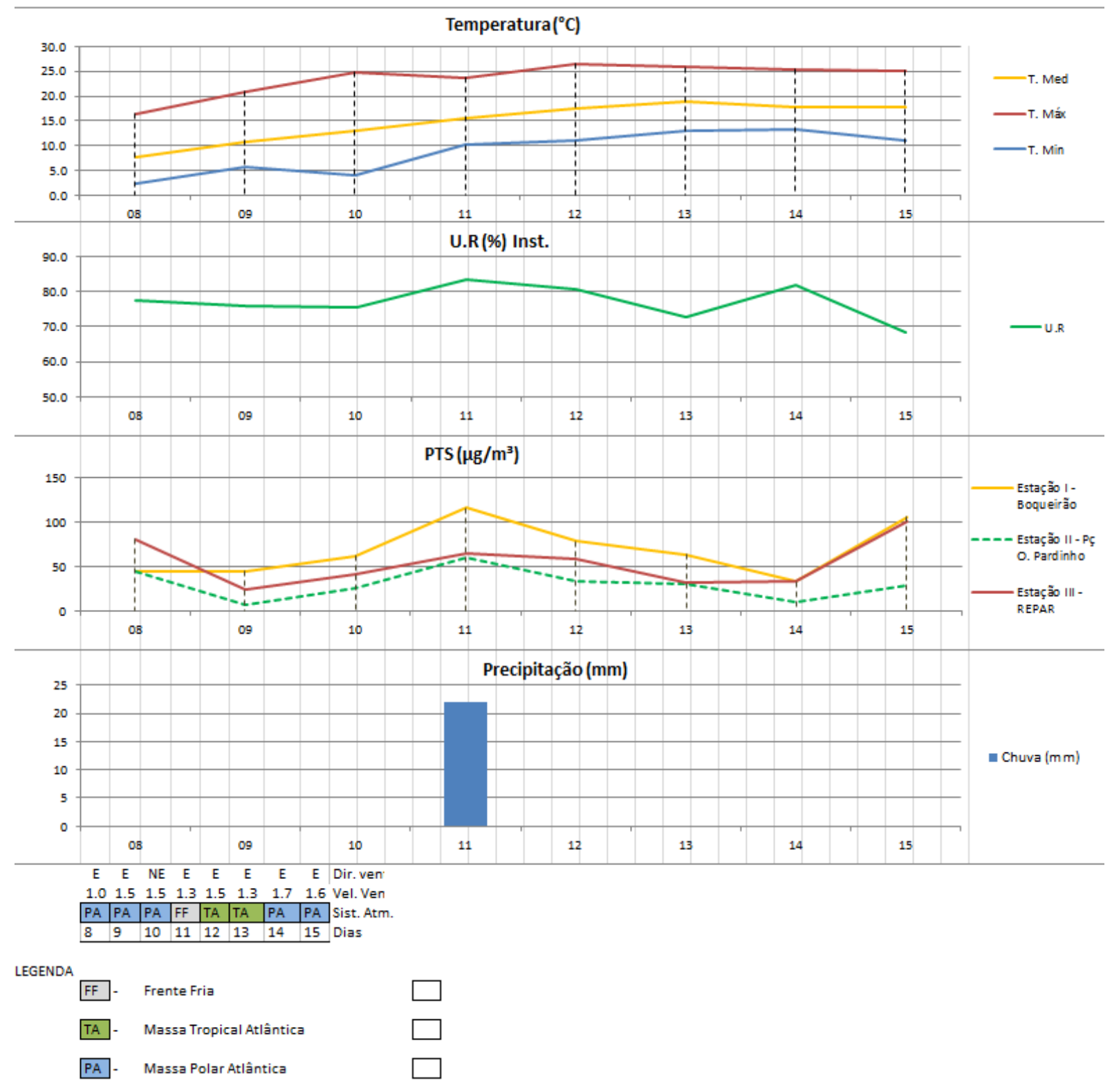

Figura 5: Curitiba: Tempo atmosférico e poluição do ar por PTS - 08 a 15/07/2011. Fonte: SIMEPAR e IAP.

Com relação ao PTS observa-se que houve pequena variação espacial. Os valores máximos foram registrados nos dias 11 e 15/07, sendo que o pico ocorreu na Estação I - Boqueirão no dia 11/07 com 115,4 $\mu \mathrm{g} / \mathrm{m}^{3}$. Após o único evento de chuva observou-se uma queda nos valores de PTS significativa nos três pontos de análise que só voltam a subir a partir do dia 15/07. Nesta data observa-se uma queda nos valores de umidade relativa do ar e a entrada de uma massa polar.

\section{A semana de 12/12 a 19/12/2011}

A semana de 12/12 a 19/12/2011 apresentou dois momentos meteorológicos distintos, repercutindo na oscilação do PTS (Figura 6). Nos quatro primeiros dias foram registrados pequenos episódios de chuva de pouca intensidade trazidos por uma Frente, e suas repercussões; em seguida, registrou-se a entrada de uma Massa Tropical Continental, responsável pela queda na umidade e manutenção da temperatura em valores altos. 


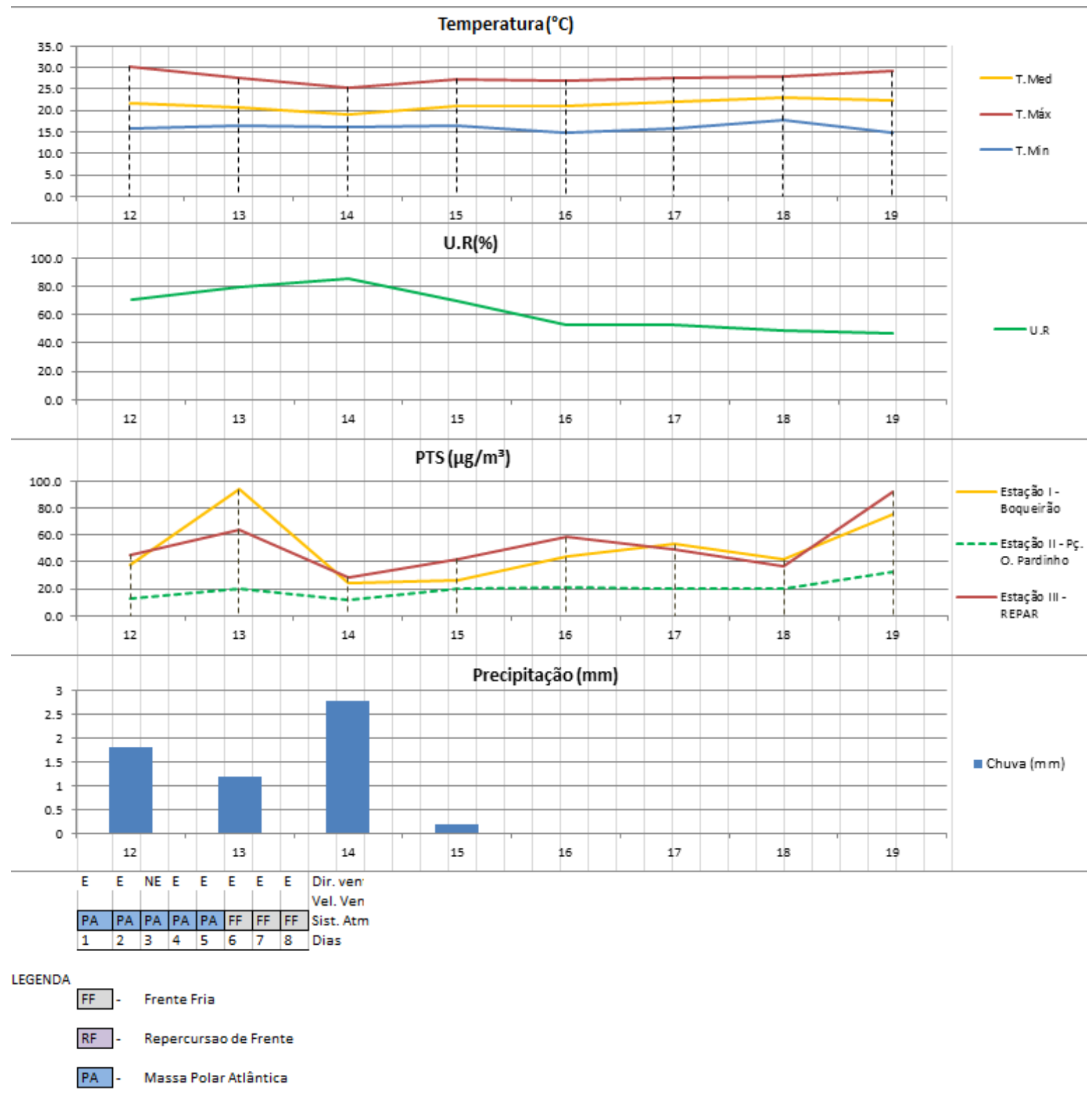

Figura 6: Curitiba: Tempo atmosférico e poluição do ar por PTS - 12 a 19/12/2011. Fonte: SIMEPAR e IAP.

O menor valor de PTS foi registrado no dia 14/12 em todas as estações, mesmo dia no qual foi registrado um episodio de chuva mais intensa ( $3 \mathrm{~mm}$ ). Após este dia, a concentração do poluente aumentou gradativamente à medida a uma queda gradativa nos valores médios de Umidade relativa do ar, em função da entrada de uma MTC.

\section{A semana de 12/12 a 19/12/2011}

O inicio da quarta semana em analise foi marcado pela atuação da Zona de Convergência do Atlântico Sul (ZCAS), que favoreceu a passagem de uma FTA - Frente Tropical Atlântica - sobre a área de estudos. Assim, nos dois primeiros dias ocorreram chuvas, alta umidade relativa do a e ventos fortes com direção leste/sudeste (Figura 7).

Os registros de PTS ao longo da semana foram fortemente influenciados pelos episódios de chuvas. No primeiro dia, com alta umidade e chuvas, os índices foram baixos; a partir do segundo, com a constante queda na umidade relativa, os valores se elevaram com o pico na estação Boqueirão $(52,7 \mu \mathrm{g} / \mathrm{dia})$ no dia 05/01. A partir do dia 07/01, com a queda de chuvas e aumento na velocidade dos ventos, os valores caíram abruptamente, culminando no dia 08/01 com os valores abaixo dos outros dias. 


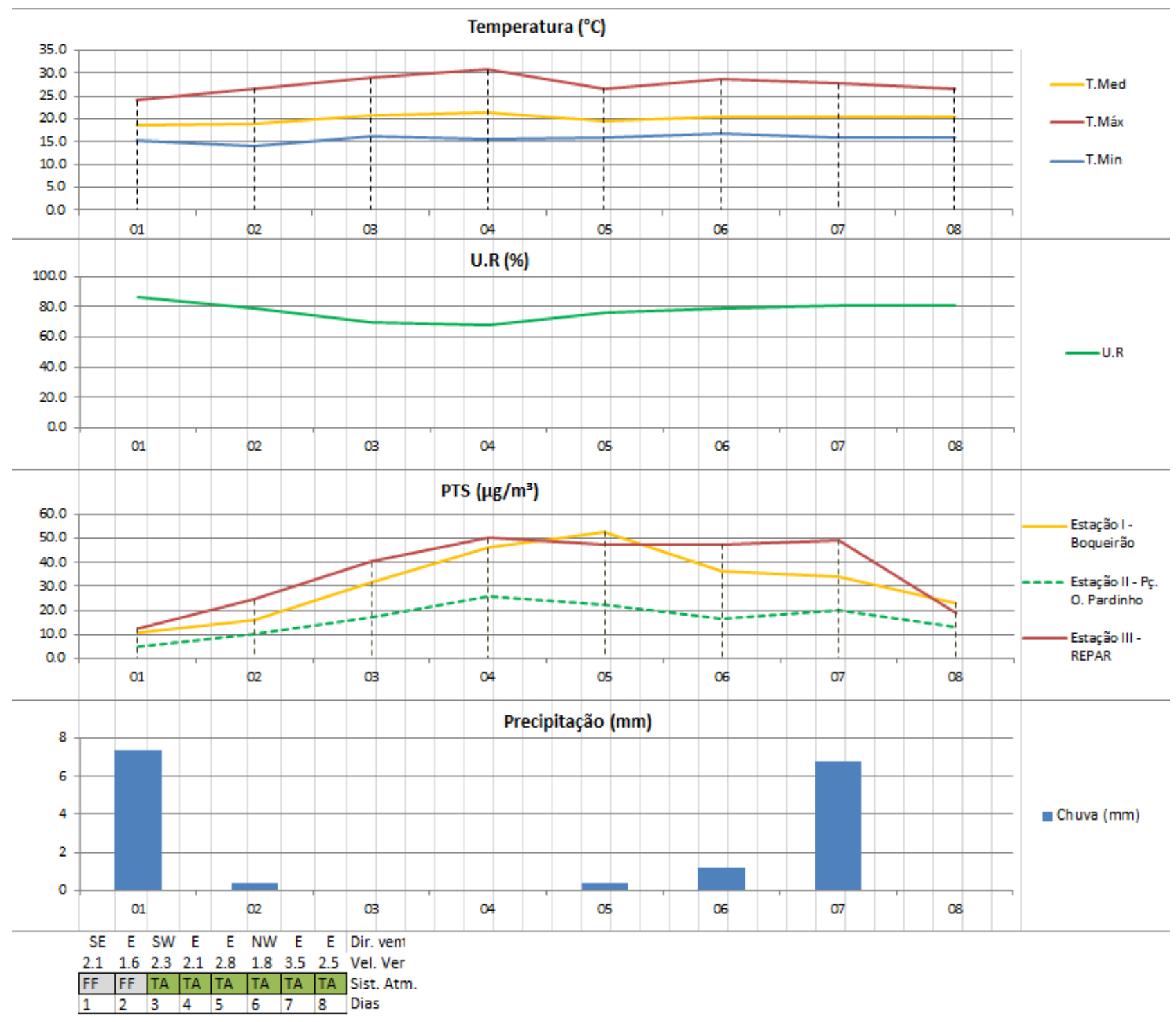

.EGENDA

FF. Frente Fria $\quad$ TA. Massa Tropical Atlântica

Figura 7: Curitiba: Tempo atmosférico e poluição do ar por PTS - 01 a 08/01/2012. Fonte: SIMEPAR e IAP.

\section{CONCLUSÕES}

Este estudo demonstra a existência de uma correlação negativa entre as Partículas Totais em Suspensão (PTS) e algumas variáveis meteorológicas, em especial a umidade relativa do ar, apontada como a variável meteorológica com maior correlação com os níveis de PTS em Curitiba. Tal fato foi observado nas três estações de monitoramento da qualidade do ar localizadas em diferentes contextos urbanos da área de estudo.

A análise de correlação estatística entre as variáveis climáticas e o PTS na cidade de Curitiba evidenciou uma considerável distinção entre altos valores, PTS e umidade (Correlações acima de 0,3) e baixos valores, PTS, pluviosidade e temperatura, (Correlações abaixo de 0,006). As variáveis meteorológicas são aqui caracterizadas como condicionantes e não determinantes para os níveis de poluição devido ao alto número de inputs no sistema ambiental da qualidade do ar, o SCU de Curitiba.

A análise da interação entre a qualidade do ar e algumas variáveis climáticas no AUC - Aglomerado Urbano de Curitiba - desenvolvida no âmbito deste breve estudo confirmou várias perspectivas teóricas, mas abriu questionamentos para outras. 
A baixa correlação observada entre o poluente e os níveis de chuva e velocidade do vento levanta questionamentos, posto que os resultados revelaram contradição às bases teóricas da analise da poluição do ar. Este resultado incita ao desenvolvimento de outros estudos visando maior aprofundamento da analise.

O exercício de se aplicar atrasos aos índices de correlação demonstrou que para a umidade relativa do ar a correlação não é imediata, e variam de estação para estação. As demais variáveis meteorológicas, contudo, não apresentaram grandes modificações nos índices de correlação com a inserção de atrasos, à exceção da velocidade do vento, posto que ficou evidente a queda nos valores conforme se aumentavam os atrasos, o que indica que tal fator tem uma ação mais imediata no PTS.

Nos períodos nos quais a área esteve sob o domínio de sistemas atmosféricos continentais observouse maior concentração e elevação nos níveis de PTS. É importante salientar ainda quanto à sazonalidade nos dados coletados: os poluentes PTS apresentam maior concentração nas semanas de inverno que na de verão,

A compreensão dos fatores espaciais também surge como determinante no entendimento da dinâmica de poluentes no AUC. Na REPAR, por exemplo, é visível a influência das áreas de indústria em seu entorno, sendo que o local ficou marcado como aquele de pior qualidade do ar de toda a RMC no que diz respeito ao PTS, registrando valores acima dos aceitáveis segundo a legislação. Deve-se ressaltar o caráter exploratório deste estudo uma vez que a área de estudo não possui pesquisa detalhada e atualizada sobre tal temática. Ressalta-se, todavia, que os dados climáticos aqui utilizados têm uma única fonte, ou seja, são provenientes de uma única estação meteorológica principal situada na porção centro-leste da cidade; um estudo com dados climáticos na micro-escala urbana, numa rede meteorológica intraurbana, poderia auxiliar na melhor compreensão da dispersão e/ou concentração da poluição do ar no AUC.

Constatou-se, por fim, que o problema da poluição do ar no AUC resulta da conjunção entre urbanização-industrialização-fluxo de veículos e condições meteorológicas propícias à concentração de poluentes na cidade. A proposta do SCU (MONTEIRO, 1976) associada a analise rítmica dos tipos de tempo mostrou-se claramente satisfatória para a elaboração deste estudo.

\section{AGRADECIMENTOS}

Ao CNPQ pelo financiamento desta pesquisa.

\section{REFERÊNCIAS}

AKPINAR, E., AKPINAR, S., OZTOP, H. Statistical analysis of meteorological factors and air pollution at winter months in Elaziğ, Turkey. Journal of Urban and Environmental Engineering, Vol. 3, N.1, p. 07$16,2009$.

BOUBEL, R. et al. Fundamentals of Air Pollution. 3. ed. San Diego, CA: Academic Press, 1994.

CARSLAW, D. C. and ROPKINS, K. Openair - an R package for air quality data analysis. Environmental Modelling \& Software. V.27-28, pp. 52-61,2012

DANNI-OLIVEIRA, I. M. A cidade de Curitiba e a Poluição do ar. Tese de doutorado, São Paulo: Universidade de São Paulo, 2000.

DERISIO, J. C. Introdução ao Controle de Poluição Ambiental. São Paulo: Ed. Oficina de Textos, 2012.

GUTJAHR, M. R. A Poluição do Ar em Paulínia (SP): Uma Analise Histórico-Geográfica do Clima. Tese de doutorado, São Paulo, Universidade de São Paulo, 2002.

HUFTY, A. Introduction a lá Climatalogie - Le rayonnement et la temperature, l'atmosphere, l'eau, le Climat et l'activité Humaine. Laval: Le Presses de L'université Laval, 2001.

MCCORMAC, B. M. Introduction to the Scientific Study of Atmospheric Pollution.Dordrecht: D. Reidel Publisinhg Company, 1971.

MENDONÇA, F. O Estudo do Clima Urbano no Brasil: Evolução, tendências e desafios. In: MONTEIRO, C.A.F.; MENDONÇA, F. (Org.) Clima Urbano. São Paulo: Editora Contexto, 2003.

MENDONÇA, F. Les inondations urbaines a Curitiba (Brésil).In: XXV Colloque de l'AIC - Association Internationale de Climatologie, 2012, Grenoble. Actes du XXV Colloque de l'AIC. Grenoble: Univ Grenoble, v. 1. 2012, p. 517-523. 
MENDONÇA, F.; DANNI-OLIVEIRA, I. M. Climatologia: Noções básicas e climas do Brasil. 1. ed. São Paulo: Editora Oficina de Textos, 2007. 208p

MENDONÇA, F. O estudo do SCU - Sistema do Clima Urbano - no Brasil: Aplicações e avanços. In: MONTEIRO,C.A.F et al. (Org.). A construção da climatologia geográfica no Brasil. 1ed.Campinas: Alínea Editora, 2015, p. 155-166.

MONTEIRO, C. A. F. Análise Rítmica em Climatologia. São Paulo: Universidade de São Paulo, 1971.

MONTEIRO, C. A. F. Teoria e clima urbano. São Paulo: Universidade de São Paulo, 1976.

MONTEIRO, C. A. F. ; MENDONÇA, F. Clima urbano. 1. ed. São Paulo: CONTEXTO, 2003. v. 1. 192p .

MONTEIRO, C. A. F. ; SANTANNA NETO, J. L. ; MENDONÇA, F. ; ZAVATTINI, J. A. . A construção da climatologia geográfica no Brasil. 1. ed. Campinas. SP: Alínea Editora, 2015. v. 1. 194p .

ROMERO, H.; IHL, M.; RIVERA, A.; ZALAZAR, P. e AZOCAR, P. Rapid Urban Growth, Land-use Changes and Air Pollution in Santiago, Chile. Atmospheric Environment, Vol. 33, p.4039-4047, 1999. 